\title{
IMPACT OF FAULT LOCATION AND DURATION ON THE STABILITY OF WIND FARM INTERCONNECTED GRID
}

\author{
Omar Noureldeen ${ }^{1}$, Mahmoud Rihan ${ }^{2}$, and Barkat Hasanin ${ }^{3}$ \\ ${ }^{1-2}$ Electrical Engineering Department, Faculty of Engineering South Valley \\ University, Qena, Egypt \\ ${ }^{3}$ Faculty of Engineering, Al-Azhar University \\ E-mail: omar_noureldeen@svu.edu.eg
}

(Received December 15, 2010 Accepted January 18, 2011)

\begin{abstract}
This paper investigates the impacts of the fault ride through on the stability of fixed speed wind farm interconnected grid. The effect of fault location and its duration time are studied for different fault types. The contribution of Static Synchronous Compensator STATCOM to support the fixed-speed wind farm interconnected electric grid during different fault locations and different fault durations are investigated. Simulation test cases using MATLAB-Simulink are implemented on a $9 \mathrm{MW}$ wind farm exports a power to $120 \mathrm{KV}$ grid. The simulation results show the influence of fault location and its duration on the active power, reactive power, and bus voltage of the wind farm.
\end{abstract}

KEYWORDS: Wind Farm, STATCOM, Fault Location, Fault Duration.

\section{INTRODUCTION}

Wind power industry is developing rapidly, more and more wind farms are being connected into power systems. In the next years, there will be more significant growth in wind energy. Although the great development in the technology of electrical generation from wind energy, there is only one way of generating electricity from wind energy is to use wind turbines that convert the energy contained in flowing air into electricity. The most currently installed wind turbines is fixed speed wind turbines which utilize squirrel cage induction generator directly connected to the grid to produce the electricity. These induction generators which are usually connected at weak end of a grid or at distribution networks draw large amount of reactive currents during disturbances such as faults. Consequently under these conditions the terminal voltage and the electrical output power are significantly reduced, whereas the mechanical torque may be still applied to the wind turbine and the rotor speed increases [1]. After fault clearance the generator needs reactive power for voltage recovery, however this reactive power has to be supplied by network which in turn causes a voltage drop, so the machine terminal voltage cannot be recovered. If the voltage could be recovered and the generator speed is not too high, torque could be restored and the wind turbine may restore its normal operation eventually. Otherwise the generator would continue to accelerate and the rotor speed and reactive power consumption will increase, so the terminal voltage decreases further. If the rotor speed exceeds a certain critical value the generator set becomes unstable, thus must be tripped out by over speed protection devices [2]. As for cases in which a large amount 
of power is supplied by generators, they are must stay connected to the grid. Therefore, the stability becomes an important problem and has recently attracted considerable attention [3]. Various methods of stability improvement have been presented by researchers. The pitch control system is used to control the power output of the wind turbine and also for stabilization of the wind turbine at grid faults. When a fault occurs in the external power system, the blade-angle control orders the mechanical system to reduce the wind turbine mechanical power to improve stability. For fixed-speed rotor short-circuited induction generators, it is not possible to control the input mechanical power, and therefore the effective approach would be the use of reactive power compensators such as STATCOM or SVC to help the voltage recovery. Squirrel cage induction generators can become easily unstable under low voltage conditions, as low terminal voltage lead to: larger rotor slip, larger reactive power consumption, further lowering of terminal voltage, and this may lead to disconnecting the turbine. Initial low voltage conditions may be originated by conditions different than faults. So that the wind turbines can be equipped with a controllable source of reactive power to deliver the reactive power required to accelerate the voltage restoration. Squirrel cage induction generators can become easily unstable under low voltage conditions, as low terminal voltage lead to: larger rotor slip, larger reactive power consumption, further lowering of terminal voltage, and this may lead to disconnecting the turbine. Initial low voltage conditions may be originated by conditions different than faults. So that the wind turbines can be equipped with a controllable source of reactive power to deliver the reactive power required to accelerate the voltage restoration [4]. Since the induction generators do not perform voltage regulation and absorb reactive power from the utility grid, they are often the source of voltage fluctuations [5]. The ability of a wind power plant to stay connected during disturbance is important to avoid the time of reconnection process, which need from 4 to 5 minutes and also to avoid cascading disturbance due to lack of generation. Furthermore it is economically convenient to handle the fault, without disconnecting the wind turbine from the grid [6], [7], [8]. It is necessary to examine the responses of squirrel cage induction generator wind farm during the faults and possible impacts on the system stability. In this paper, the impacts of fault location and its duration time on $9 \mathrm{MW}$ wind farm interconnected grid are studied by monitoring the active power, reactive power, and bus voltage of the wind farm. Also, the contribution of STATCOM to support the wind farm during different fault locations and durations are studied.

\section{MODEL OF WIND TURBINE SYSTEM}

\subsection{Wind Turbine Model}

The mechanical power and the aerodynamic torque developed by a wind turbine are given by

$$
P_{w}=\frac{\pi \rho r^{2}}{2} v_{\text {wind }}^{3} C_{p}(\lambda, \beta)
$$

Where $P_{w}$ is the mechanical output power captured from the turbine (watt), $\rho$ is the air density $\left(\mathrm{kg} / \mathrm{m}^{3}\right), r$ is the radius of the turbine $(\mathrm{m}), v_{\text {wind }}$ is the wind speed $(\mathrm{m} / \mathrm{s})$, $C_{P}$ is the power coefficient of the wind turbine, $\beta$ is the pitch angle and $\lambda$ is the tip speed ratio [5]. Where the tip speed ratio is defined as 


$$
\lambda=\frac{\omega_{m} r}{v}
$$

Where, $\omega_{\mathrm{m}}$ is the angular speed of turbines ( $\left.\mathrm{rad} / \mathrm{s}\right)$. One of the methods used to calculate the power coefficient $C_{P}$ by using a generic equation is [4]:

$$
C_{p}(\lambda, \beta)=0.5176\left(\frac{116}{\lambda_{i}}-0.4 \beta-5\right) e^{\frac{-0.0068}{\lambda_{i}}}+0.0068 \lambda
$$

Where ${ }^{\lambda}$ is given by:

$$
\frac{1}{\lambda_{i}}=\frac{1}{\lambda+0.08 \beta}-\frac{0.035}{\beta^{3}+1}
$$

\subsection{Generators Model}

According to a standard per-unit notation [9], in the synchronously rotating frame, the induction generator can be represented by the detailed differential equations of the flux linkages. All stator and rotor quantities are in the arbitrary two-axis reference frame (d$\mathrm{q}$ frame). The used subscripts are defined as follows: $\mathrm{d}$ : $\mathrm{d}$ axis quantity, q: q axis quantity, r: rotor quantity, s: stator quantity.

$$
\begin{gathered}
v_{s d}=-R_{s} i_{s d}-\omega_{s} \psi_{s q}+\frac{1}{\omega_{B}} p \psi_{s d} \\
v_{s q}=-R_{s} i_{s q}+\omega_{s} \psi_{s d}+\frac{1}{\omega_{B}} p \psi_{s q} \\
v_{r d}=-R_{r} i_{r d}-s \omega_{s} \psi_{r q}+\frac{1}{\omega_{B}} p \psi_{r d} \\
v_{r q}=-R_{r} i_{r q}+s \omega_{s} \psi_{r d}+\frac{1}{\omega_{B}} p \psi_{r q}
\end{gathered}
$$

Where $\omega_{\mathrm{S}}$ is the synchronous speed (in per-unit, $\omega_{\mathrm{S}}=1$ ); $\omega_{\mathrm{B}}$ is the system base frequency which is equal to the synchronous frequency, $\omega_{\mathrm{B}}=2 \pi \mathrm{f} ; \mathrm{p}$ is the $\mathrm{d} / \mathrm{dt}$ operator. The electromagnetic torque, $T_{\mathrm{e}}$ can be expressed as

$$
T_{e}=L_{m}\left(i_{s d} i_{r q}-i_{s q} i_{r d}\right)
$$

The constitutive flux linkage current relationships are

$$
\begin{gathered}
\psi_{s d}=-L_{s s} i_{s d}-L_{m} i_{r d} \\
\psi_{s q}=-L_{s s} i_{s q}-L_{m} i_{r q} \\
\psi_{r d}=-L_{m} i_{s d}-L_{r r} i_{r d} \\
\psi_{s d}=-L_{m} i_{s q}-L_{r r} i_{r q}
\end{gathered}
$$

Where, $\mathrm{L}_{\mathrm{ss}}$ is the summation of leakage inductance $\mathrm{L}_{1}$ and mutual inductance $\mathrm{L}_{\mathrm{m}}$.

Considered generators are usually represented as a voltage source behind transient impedance in power system stability studies, the detailed transient model of SCIG can be established as (where the $\mathrm{d}$ and q components of rotor voltage are zero, respectively). 


$$
\begin{aligned}
\frac{X^{\prime}}{\omega_{s} \omega_{B}} p i_{s d}= & -\left(R_{s}+\frac{X-X^{\prime}}{T_{O}}\right) i_{s d}+X^{\prime} i_{s q} \\
& +(1-s) E_{d}-\frac{1}{T_{O}} E_{q}-v_{s d} \\
\frac{X^{\prime}}{\omega_{s} \omega_{B}} p i_{s q}= & -\left(R_{s}+\frac{X-X^{\prime}}{T_{O}}\right) i_{s q}+X^{\prime} i_{s d} \\
& +(1-s) E_{q}-\frac{1}{T_{O}} E_{d}-v_{s q} \\
\frac{1}{\omega_{s} \omega_{B}} p E_{d}= & -\frac{1}{T_{O}}\left(E_{d}-\left(X-X^{\prime}\right) i_{s q}\right)+s E_{q} \\
T_{e}= & E_{d} i_{s d}+E_{q} i_{s q}
\end{aligned}
$$

Where,

$$
X=\omega_{s} L_{s s} ; X^{\prime}=\omega_{s}\left(L_{s s}-\frac{L_{m}^{2}}{L_{r r}}\right) ; T_{0}=\frac{L_{r r}}{\omega_{s} R_{r}} ; E_{d}=\frac{\omega_{s} L_{m}}{L_{r r}} \psi_{r q} ; E_{q}=\frac{\omega_{s} L_{m}}{L_{r r}} \psi_{r d}
$$

\subsection{Drive Train Model}

Considering the features of low stiffness of the shaft between the turbine and generator, the two-mass drive train models can be expressed as

$$
\begin{aligned}
2 H_{M} \frac{d \omega_{M}}{d t} & =T_{m}-K_{s} \theta_{s} \\
2 H_{G} \frac{d \omega_{G}}{d t} & =K_{s} \theta_{s}-T_{e} \\
\frac{d \theta_{S}}{d t} & =\omega_{B}-\left(\omega_{M}-\omega_{G}\right)
\end{aligned}
$$

where, $H_{M}$ and $H_{G}$ are the inertia constant of the wind turbine rotor and the generator rotor respectively. $\omega_{M}$ and $\omega_{G}$ are the wind turbine and generator speed respectively. $K_{s}$ is the shaft stiffness and $\theta_{s}$ is the shaft tensional twist angle.

\section{STATCOM MODEL}

Figure 1 shows the basic model of a STATCOM connected to the wind farm bus through a coupling transformer. The STATCOM is designed using a power electronic voltage source converter VSC. The function of the VSC is a fully controllable voltage source matching the system voltage in phase, frequency, and with amplitude which can be continuously and rapidly controlled, so as to be used as the tool for reactive power control.

The VSC can inject or absorb reactive power to/from the bus where it is connected via a coupling transformer. The output of the controller Qc is controllable which is proportional to the voltage magnitude difference $(\mathrm{Vc}-\mathrm{V})$ and is given by the following equation

$$
Q_{c}=\frac{V\left(V_{c}-V\right)}{X}
$$




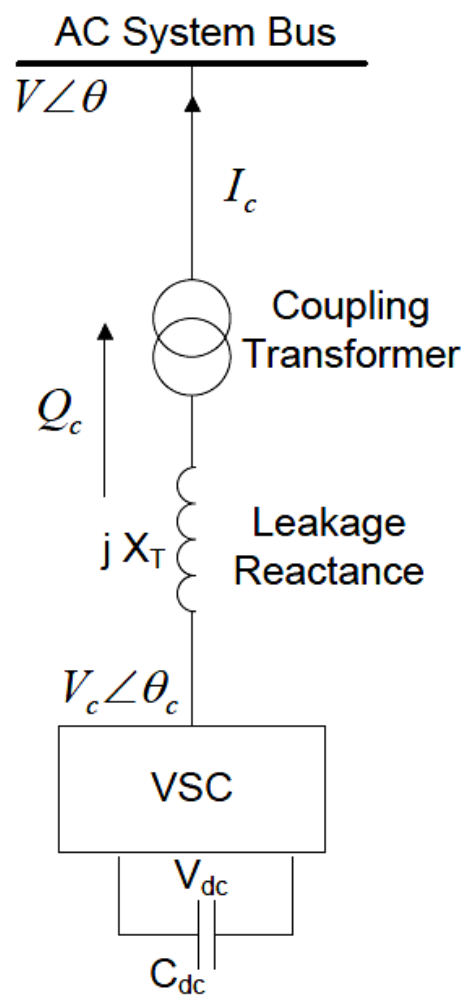

Fig. 1: Basic model of a STATCOM

\section{CASE STUDY}

\subsection{Studied System Description}

Figure 2 shows a single line diagram of a typical fixed speed wind power plant under study. A simulation model of a wind farm consisting of six 1.5 MW wind turbines is connected to a $25 \mathrm{kV}$ distribution system exports power to a $120 \mathrm{kV}$ grid through a 25 $\mathrm{kV}$ feeder. The $9 \mathrm{MW}$ wind farm is simulated by three pairs of $1.5 \mathrm{MW}$ SCIG wind turbines. The stator winding is connected directly to the $60 \mathrm{~Hz}$ grid and the rotor is driven by a variable pitch wind turbine. The pitch angle is controlled in order to limit the generator output power at its nominal value for winds exceeding the nominal speed $(9 \mathrm{~m} / \mathrm{s})$. Fixed capacitor banks are connected at low voltage bus of each wind turbine (400 KVAR for each pair of 1.5 MW turbines) which supplies the constant no load demand. The simulation model is carried out using the MATLAB SimPowerSystems toolbox. The bus B25 is the main bus (collected bus) of the wind farm which connects the wind farm with the grid, so in this paper this bus is taken as the monitoring point of the whole studied wind farm.

The monitoring equipments (measurement equipments) are placed at the main bus B25 for monitoring: the total exported (generated) active power from the wind farm to the grid, the total absorbed reactive power from the grid and the terminal voltage at the main bus of the wind farm. Each wind turbine has a protection system monitoring voltage, current and generator speed. The set parameters of the protection 
system are illustrated in Appendix A. The wind farm must stay connected during fault, with the voltage at interconnection point dropping to zero for the duration of nine cycles (150 ms based on $60 \mathrm{~Hz}$ frequency) [10]. This time is generally needed for the transmission system protective equipment to clear the fault. Therefore, to study the effect of fault duration it must not exceed than $150 \mathrm{~ms}$.

\subsection{Simulation Scenario}

The system is studied at steady state condition and fault state condition. At the fault state, the voltage, active power and reactive power are monitored at collected bus B25. The behavior of the wind power plant is recorded during fault events, including prefaults and post-fault events. The studied wind farm operates at the nominal wind speed of $9 \mathrm{~m} / \mathrm{s}$, so the wind turbines operate at nominal values. During fault period, it can be assumed that the wind speed does not change.

To study the effect of fault location, the simulation is performed when the fault occurs at points P1 and P2 as shown in Fig. 2. The first fault location at the point P1 about $1 \mathrm{~km}$ from the wind turbines and the second fault location at the point P2, about $25 \mathrm{~km}$ from the main wind farm collected bus B25. In this paper, the fault duration times are varied between $80 \mathrm{~ms}$ and $150 \mathrm{~ms}$. The system is studied twice: one without STATCOM connection, and the other with STATCOM connection.

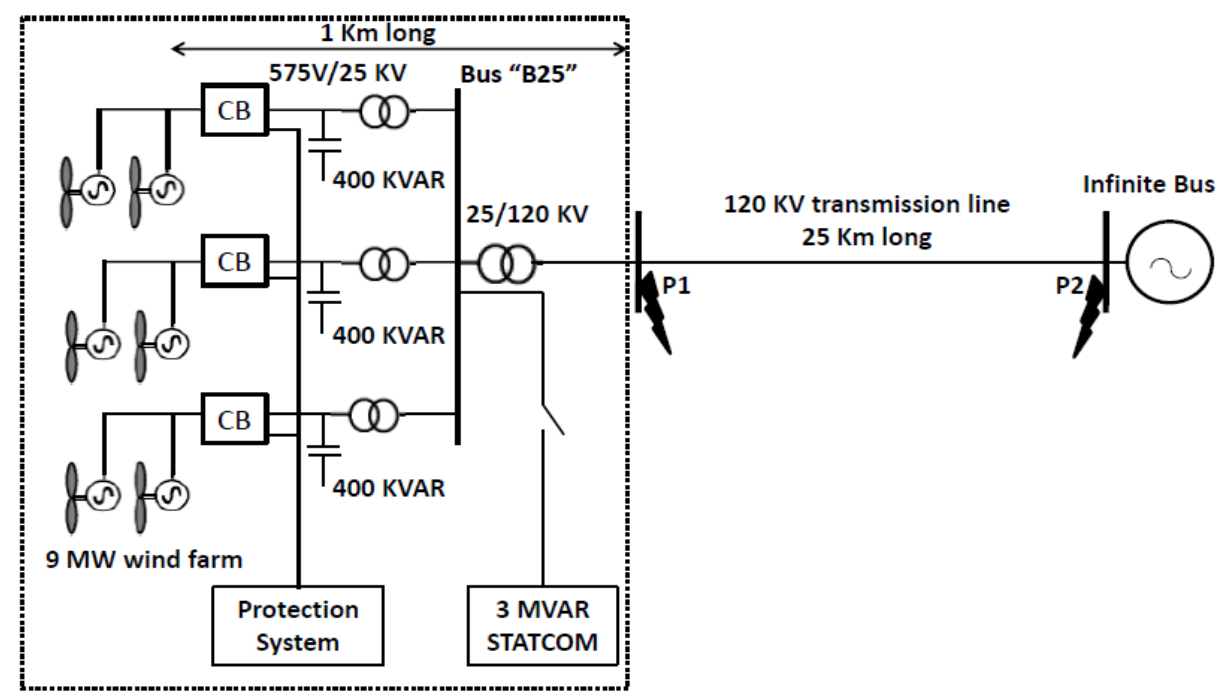

Fig. 2: Single line diagram of the studied system

\section{SIMULATION RESULTS AND ANALYSIS}

The effect of fault location and its duration on the stability of the wind farm connected grid are studied for different fault types as single line to ground fault, double line to ground fault, and three-line to ground fault. To study the effect of fault location on the behavior of the wind farm, the operation of the wind farm under different fault types are monitored twice, one when the fault occurs at the first fault location P1 about $1 \mathrm{~km}$ from wind turbines, and the other when the fault occurs at the second fault location P2 about $26 \mathrm{~km}$ from wind turbines. Also, to study the effect of fault duration time on the 
behavior of the wind farm, the operation of the wind farm under different fault duration times is monitored when the fault occurs at the point P1. The fault duration time is varied between 80 and $150 \mathrm{~ms}$. The effect of a 3 MVAR STATCOM on the behavior of the wind farm is studied for all cases.

\subsection{Effect of Fault Location}

Figure 3 shows the variation of wind farm terminal voltage, generated active power, and absorbed reactive power when a single line to ground fault occurs at the points P1 and P2. During fault period, the voltage of the main bus B25 is decreased to $0.8017 \mathrm{pu}$ when the fault occurs at point P1, and it decreases to $0.8541 \mathrm{pu}$ when the fault occurs at point P2. Also, the total exported active power at bus B25 decreases to $7.8329 \mathrm{MW}$ when the fault occurs at point P1, and it decreases to $7.8523 \mathrm{MW}$ when the fault occurs at point P2. The total absorbed reactive power from the grid at the post fault period is increased; this increasing when the fault occurs at point P1 is 4.4041 MVAR while in the case of second fault location P2, it is increased to 4.0937 MVAR. As shown in Fig. 3 , it is clear that the wind power plant has the ability to stay connected under this fault condition without STATCOM connection either when the fault occurs at P1 or P2.
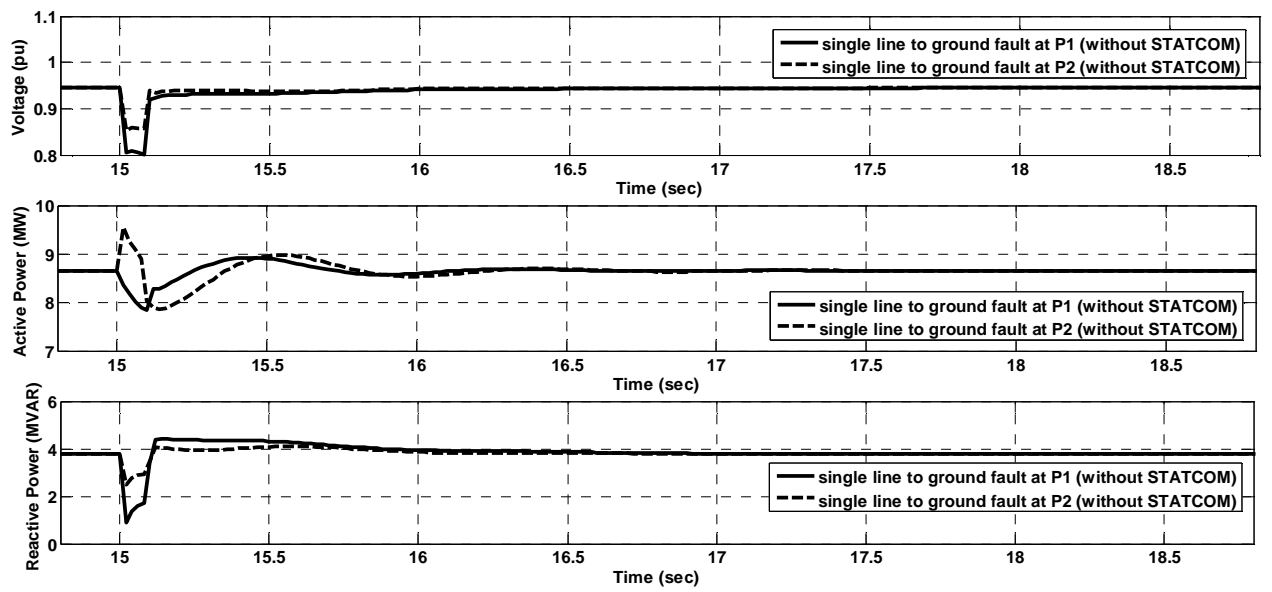

Fig. 3: The variations of the voltage, active power, and total absorbed reactive power during single line to ground fault at different fault locations - without STATCOM.

Figure 4 shows the variation of wind farm terminal voltage, generated active power and absorbed reactive power in case of single line to ground fault occurs at the points P1 and P2 in present of STATCOM. During fault period, the voltage of the main bus $\mathrm{B} 25$ is decreased to 0.8542 pu when the fault occurs at point P1, and it decreases to $0.9150 \mathrm{pu}$ when the fault occurs at point P2. Also, the total exported active power at bus B25 decreases to $7.9821 \mathrm{MW}$ when the fault occurs at point P1, and it decreases to 8.0014 MW when the fault occurs at point P2. The total absorbed reactive power from the grid at the post fault period is increased; this increasing when the fault occurs at point P1 is 2.1884 MVAR while in the case of second fault location P2 it is increased to 1.9884 MVAR. It is clear that, the STATCOM enhances the wind farm terminal voltage. Also the absorbed reactive power from the grid is decreased. 

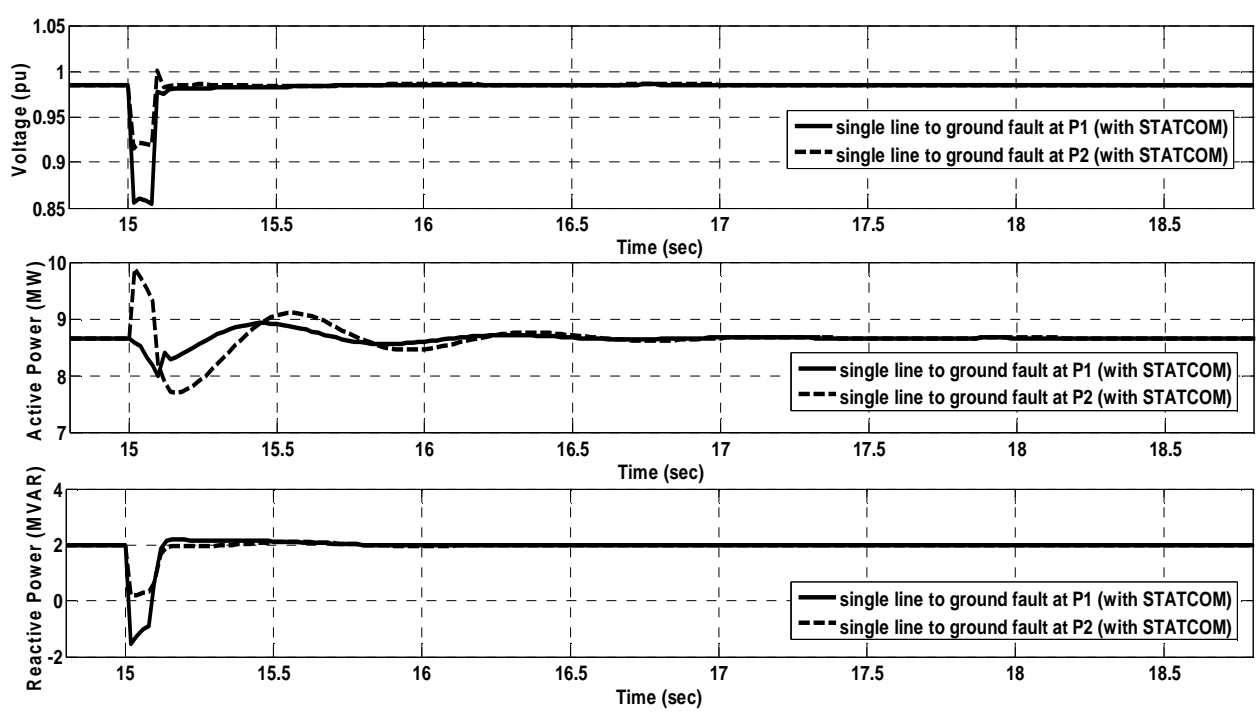

Fig. 4: The variations of the voltage, active power, and total absorbed reactive power during single line to ground fault at different fault locations - with STATCOM.

Figure 5 shows the variation of wind farm terminal voltage, generated active power and absorbed reactive power in case of double line to ground fault occurs at the points P1 and P2. During fault period, the voltage of the main bus B25 is decreased to $0.4035 \mathrm{pu}$ when the fault occurs at point P1, and it decreases to $0.5499 \mathrm{pu}$ when the fault occurs at point P2. Also, the total exported active power at bus B25 decreases to 3.8244 MW when the fault occurs at point P1, and it decreases to 4.9580 MW when the fault occurs at point P2. The total absorbed reactive power from the grid at the post fault period is increased; this increasing when the fault occurs at point P1 is 6.3629 MVAR, while in the case of second fault location P2 it is increased to 5.734 MVAR.

As shown in Fig. 5, it is clear that the wind power plant has the ability to stay connected to grid in case of double line to ground fault without STATCOM connection, either when the fault occurs at the first fault location P1 or when the fault occurs at the second fault location P2, then at the both cases after the end of post fault period, the system returns back to steady state operation as the pre-fault period.

Figure 6 shows the variation of wind farm terminal voltage, generated active power and absorbed reactive power when a double line to ground fault occurs at the points P1 and P2 in present of STATCOM. During fault period, the voltage of the main bus $\mathrm{B} 25$ is decreased to 0.4336 pu when the fault occurs at point P1, and it decreases to $0.6061 \mathrm{pu}$ when the fault occurs at point P2. Also, the total exported active power at bus B25 decreases to $3.9451 \mathrm{MW}$ when the fault occurs at point P1, and it decreases to 5.4154 MW when the fault occurs at point P2. The total absorbed reactive power from the grid at the post fault period is increased; this increasing when the fault occurs at point P1 is 4.0008 MVAR while in the case of second fault location P2 it is increased to 3.1033 MVAR. 

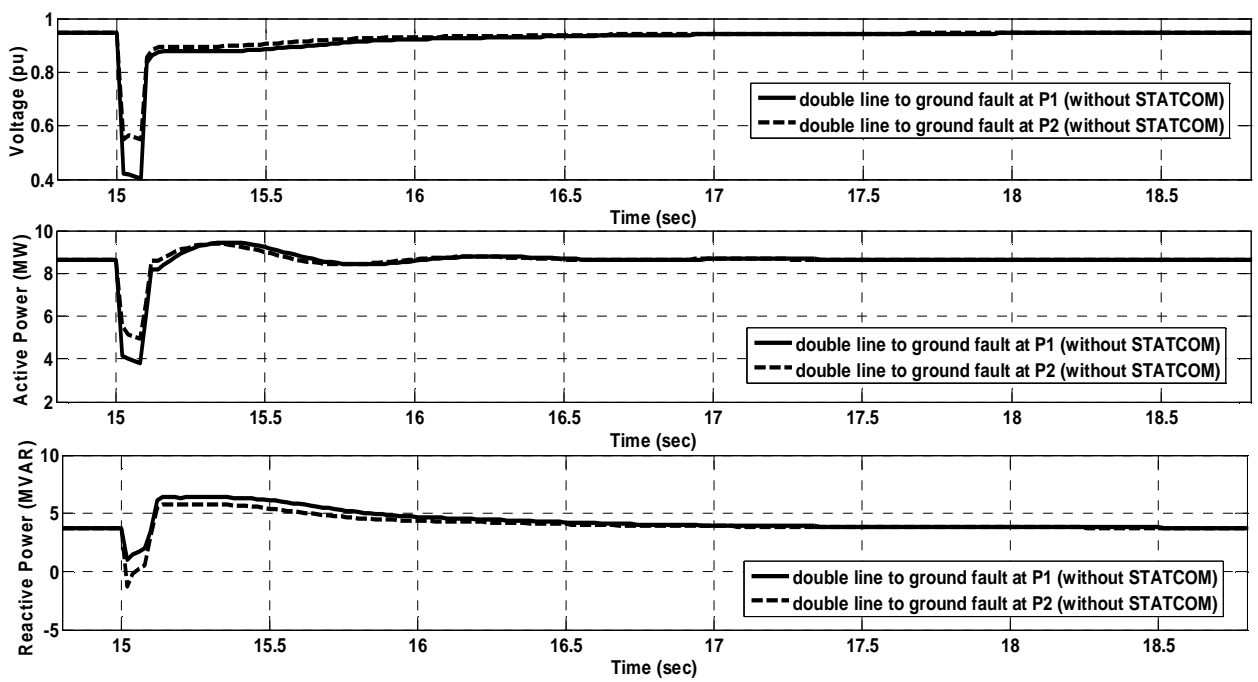

Fig. 5: The variations of the voltage, active power, and total absorbed reactive power during double line to ground fault at different fault locations - without STATCOM.
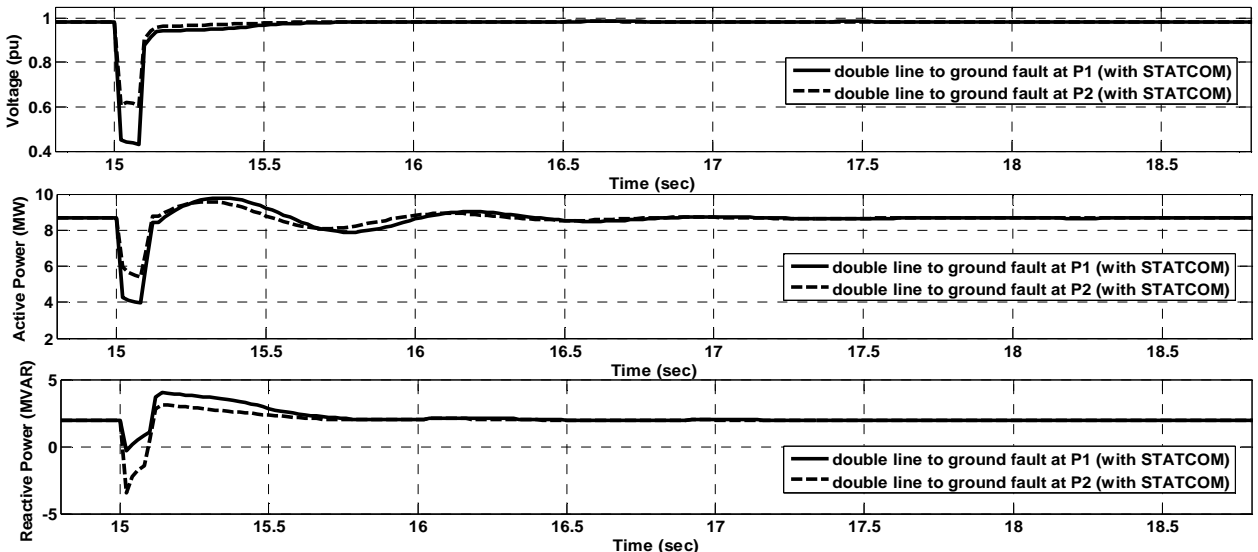

Fig. 6: The variations of the voltage, active power, and total absorbed reactive power during double line to ground fault at different fault locations - with STATCOM.

The effect of three-line to ground fault on the behavior of the wind farm is shown in Fig. 7 and Fig. 8. As shown in Fig. 7 when the system operates without STATCOM, the main bus voltage falls to zero when the fault occurs at point P1, and it decreases to $0.2171 \mathrm{pu}$ when the fault occurs at point P2. Also, the total exported active power at bus B25 falls to zero when the fault occurs at point P1, so the protection system trips the wind farm because the under voltage duration time exceeding the protection delay time. The generated active power decreases to 0.8594 MW when the fault occurs at point P2. During post fault period the total absorbed reactive power from the grid is -1.2735 MVAR when the fault occurs at point $\mathrm{P} 1$, it is the reactive power which generated by the fixed capacitor. When the fault occurs at point $\mathrm{P} 2$, the absorbed reactive power is increased to 7.6580 MVAR. It is clear that, when the STATCOM is disconnected the wind farm cannot stay connected to the grid in case of three line to ground fault occurs at point P1 but it has the ability to stay connected to the grid when the fault occurs at point $\mathrm{P} 2$. 

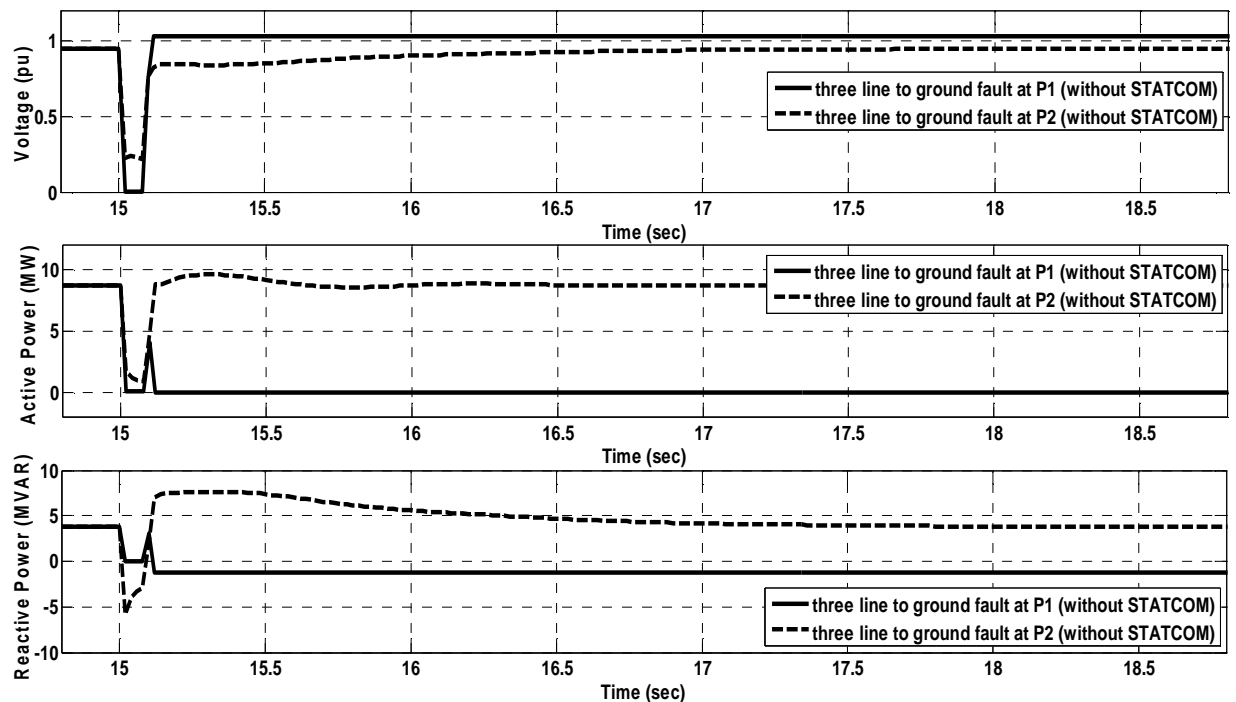

Fig. 7: The variations of the voltage, active power, and total absorbed reactive power during three-line to ground fault at different fault locations - without STATCOM.

Figure 8 shows the effect of three-line to ground fault on the wind farm behavior when the STATCOM is connected. During fault period, the voltage of the main bus B25 falls to zero when the fault occurs at point P1 and it decreases to 0.2742 pu when the fault occurs at point P2. Also, the total exported active power at bus B25 falls to zero when the fault occurs at point P1, and it decreases to $1.2666 \mathrm{MW}$ when the fault occurs at point P2. The total absorbed reactive power from the grid at the post fault period is increased; this increasing when the fault occurs at point P1 is 6.1798 MVAR, while in the case of second fault location P2 it is increased to 5.1214 MVAR. When the STATCOM is connected the wind power farm has the ability to stay connected under three-line to ground fault when the fault occurs at the first fault location P1 or when the fault occurs at the second fault location P2. In the presence of STATCOM, the main bus voltage collapse time is less than the protection system delay time, therefore the wind farm stay connected to the grid.
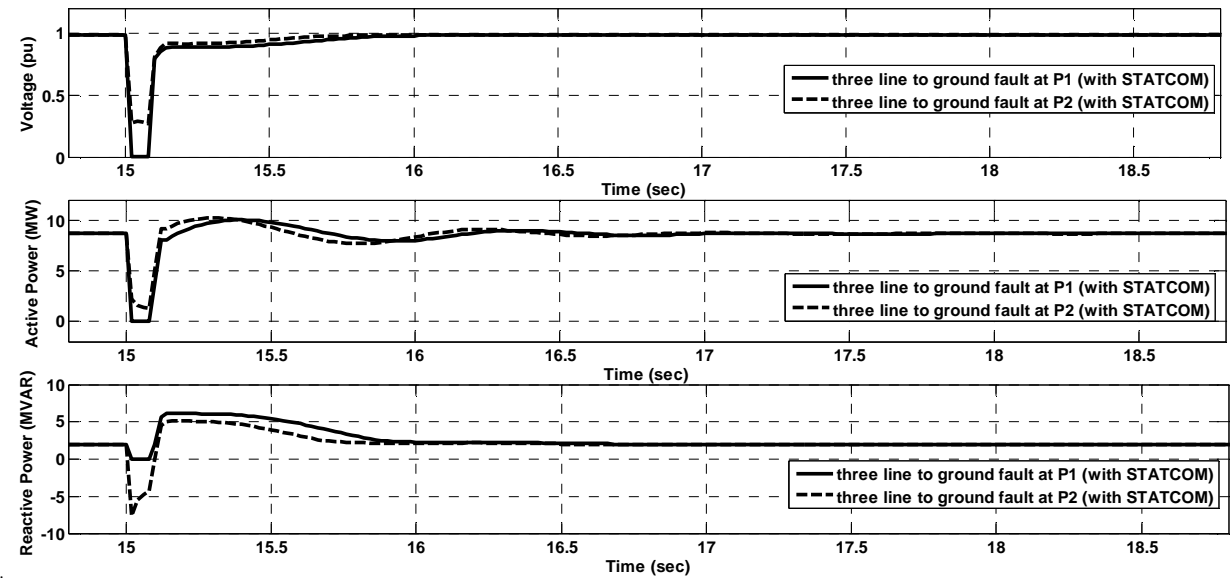

Fig. 8: The variations of the voltage, active power, and total absorbed reactive power during three-line to ground fault at different fault locations - with STATCOM. 


\subsection{Effect of Fault Duration}

In this section the effect of fault duration time is studied for the different fault types. Fig. 9 shows the behavior of the wind farm when a single line to ground fault occurs for $88 \mathrm{~ms}$ and $150 \mathrm{~ms}$ duration times. As shown in Fig. 9, during fault period the voltage of the main bus B25 is decreased to 0.8017 pu when the fault duration time is $88 \mathrm{~ms}$, and it is decreased to $0.7929 \mathrm{pu}$ when the fault duration time is $150 \mathrm{~ms}$. Also, the total exported active power from the wind farm is decreased, this decreasing in the case of $88 \mathrm{~ms}$ is $7.8330 \mathrm{MW}$ and it decreases to $7.6865 \mathrm{MW}$ in the case of $150 \mathrm{~ms}$ fault duration. During post fault period, the total absorbed reactive power from the grid is increased to $4.4041 \mathrm{MVAR}$ in the case of $88 \mathrm{~ms}$ fault duration, and it increases to 4.8292 MVAR in the case of $150 \mathrm{~ms}$ fault duration. It is clear that, the wind power plant has the ability to stay connected under this fault condition without STATCOM connection either when the fault occurs for $88 \mathrm{~ms}$ or $150 \mathrm{~ms}$, so at both cases the system returns back to steady state operation.
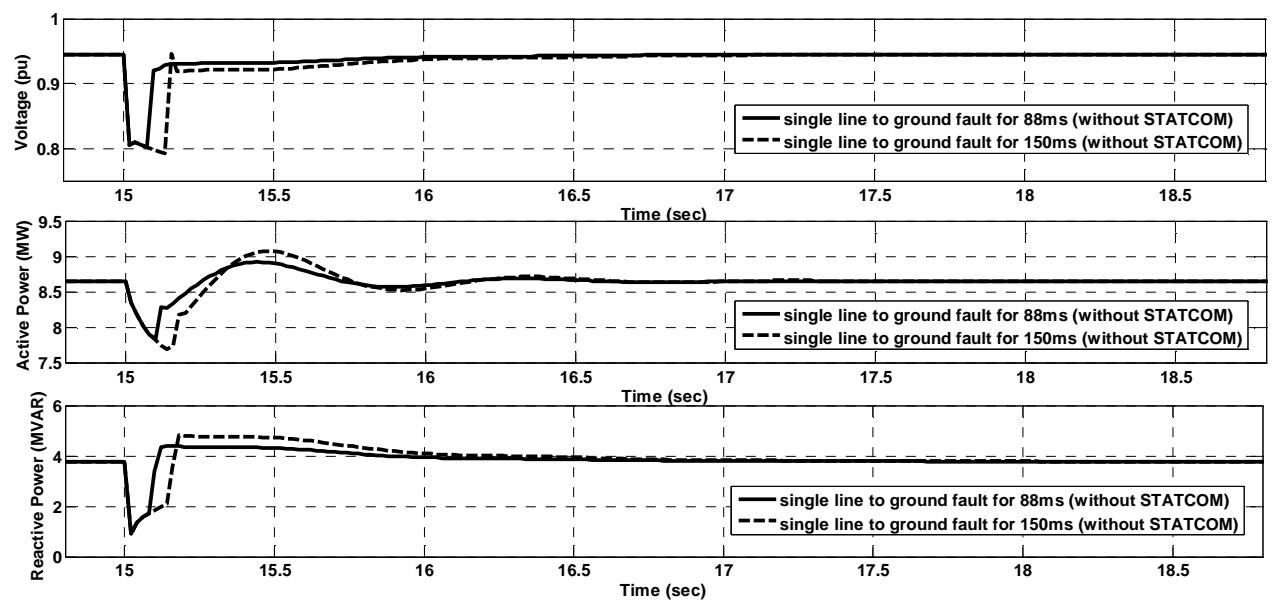

Fig. 9: The variations of the voltage, active power, and total absorbed reactive power during single line to ground fault at different fault durations - without STATCOM.

Figure 10 shows the effect of fault duration time on the behavior of the wind farm in presence of STATCOM in case of single line to ground fault. During fault period, the voltage of the main bus B25 is decreased to $0.8543 \mathrm{pu}$ when the fault duration is $88 \mathrm{~ms}$, and it decreases to $0.8466 \mathrm{pu}$ when the fault duration time is $150 \mathrm{~ms}$. Also, the total exported active power from the wind farm is decreased to $7.9821 \mathrm{MW}$ in case of $88 \mathrm{~ms}$ fault duration, and it decreases to $7.9162 \mathrm{MW}$ in case of $150 \mathrm{~ms}$ fault duration. During post fault period, the total absorbed reactive power from the grid is increased to $2.1831 \mathrm{MVAR}$ in case of $88 \mathrm{~ms}$ fault duration, and it increases to 2.3033 MVAR in case of $150 \mathrm{~ms}$ fault duration. It is clear that, in case of single line to ground fault, the wind power farm has the ability to stay connected under this fault condition with and without 3 MVAR STATCOM connection either when the fault occurs for 88 $\mathrm{ms}$ or $150 \mathrm{~ms}$. Also, the system returns back to steady state operation after clearing the fault. 

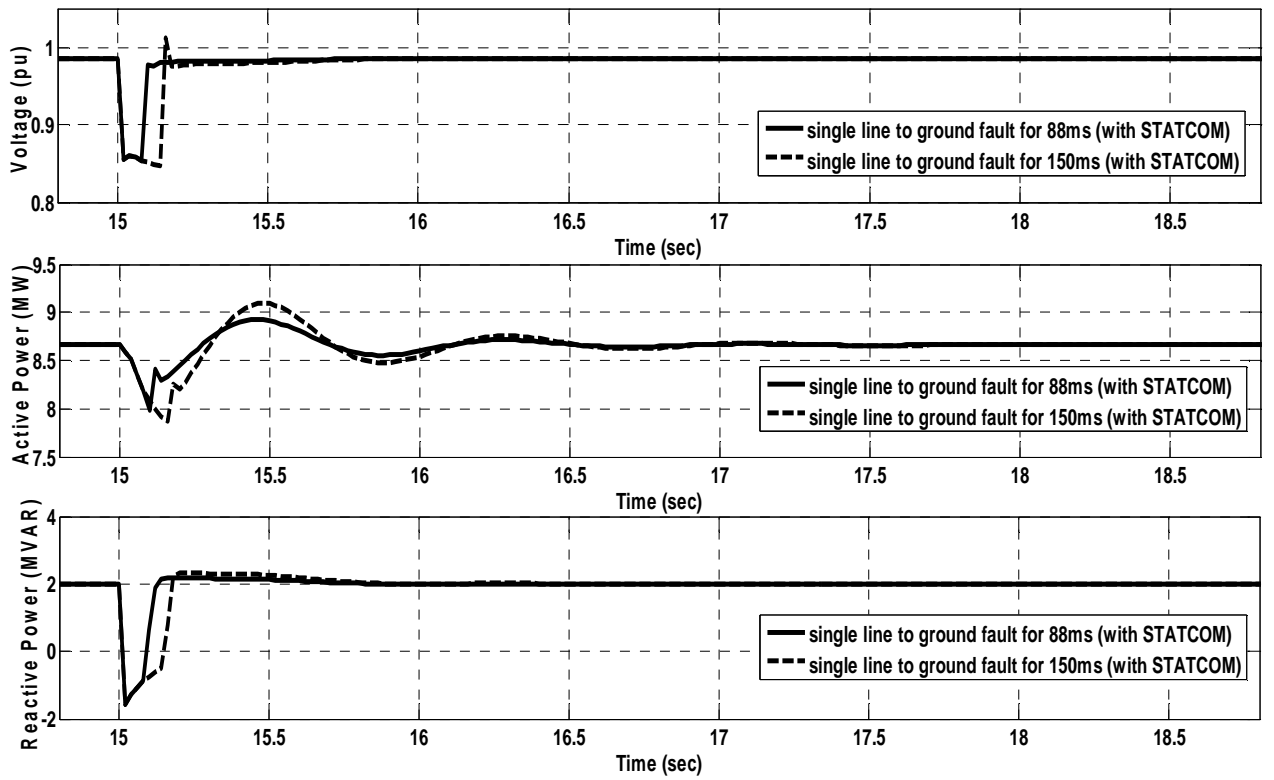

Fig. 10: The variations of the voltage, active power, and total absorbed reactive power during single line to ground fault at different fault durations - with STATCOM.

Figure 11 shows the behavior of the wind farm without STATCOM when a double line to ground fault occurs for $88 \mathrm{~ms}$ and $97 \mathrm{~ms}$ duration times. As shown in Fig. 11, during fault period the voltage of the main bus B25 is decreased to $0.4035 \mathrm{pu}$ when the fault duration times are $88 \mathrm{~ms}$ and $97 \mathrm{~ms}$. When the fault duration time is equal or more than $97 \mathrm{~ms}$ the protection system trips the wind farm and the generated active power falls to zero. During post fault period, the absorbed reactive power increased to 6.3629 MVAR in case of $88 \mathrm{~ms}$ fault duration. In case of $97 \mathrm{~ms}$ fault duration, the measured reactive power value is -1.2735 MVAR, it is the reactive power generated by the fixed capacitor bank, and it leads to enhancing of the bus voltage value.

Figure 12 shows the effect of double line to ground fault duration time on the behavior of the wind farm in the presence of STATCOM. During fault period, the voltage of the main bus is decreased to 0.4336 pu when the fault duration is $88 \mathrm{~ms}$, and it decreases to $0.4302 \mathrm{pu}$ when the fault duration time is $97 \mathrm{~ms}$. Also, the total exported active power from the wind farm is decreased to $3.9451 \mathrm{MW}$ in case of $88 \mathrm{~ms}$ fault duration, and it decreases to $3.1095 \mathrm{MW}$ in case of $97 \mathrm{~ms}$ fault duration. During post fault period, the total absorbed reactive power from the grid is increased to 4.0008 MVAR in case of $88 \mathrm{~ms}$ fault duration, and it increases to 4.2877 MVAR in case of 97 $\mathrm{ms}$ fault duration. It is clear that, in case of double line to ground fault, the wind power farm has the ability to stay connected under this fault condition with and without STATCOM connection either when the fault occurs for $88 \mathrm{~ms}$ or $97 \mathrm{~ms}$ fault duration time. Also, the system returns back to steady state operation after clearing the fault. 

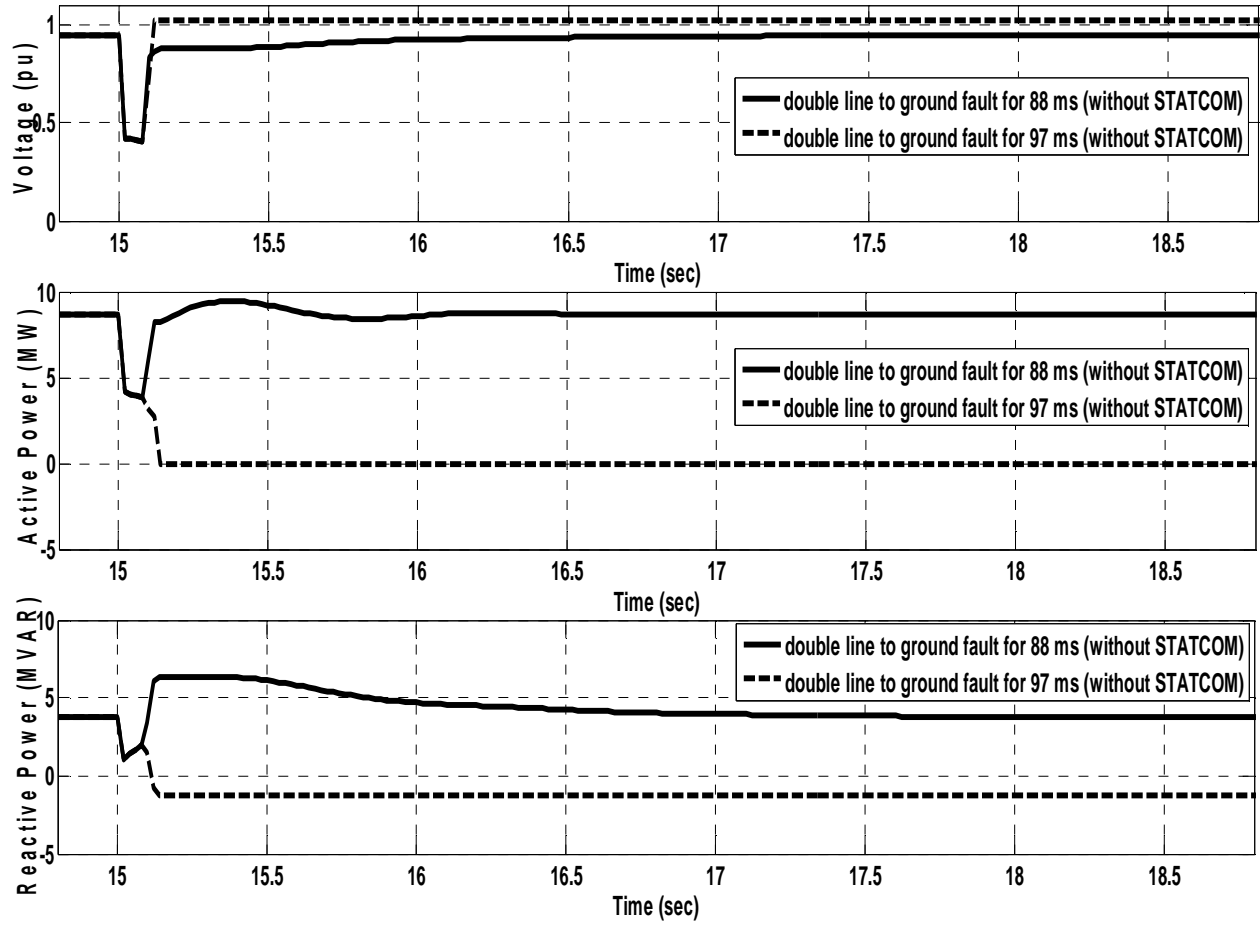

Fig. 11: The variations of the voltage, active power, and total absorbed reactive power during double line to ground fault at different fault durations - without STATCOM.
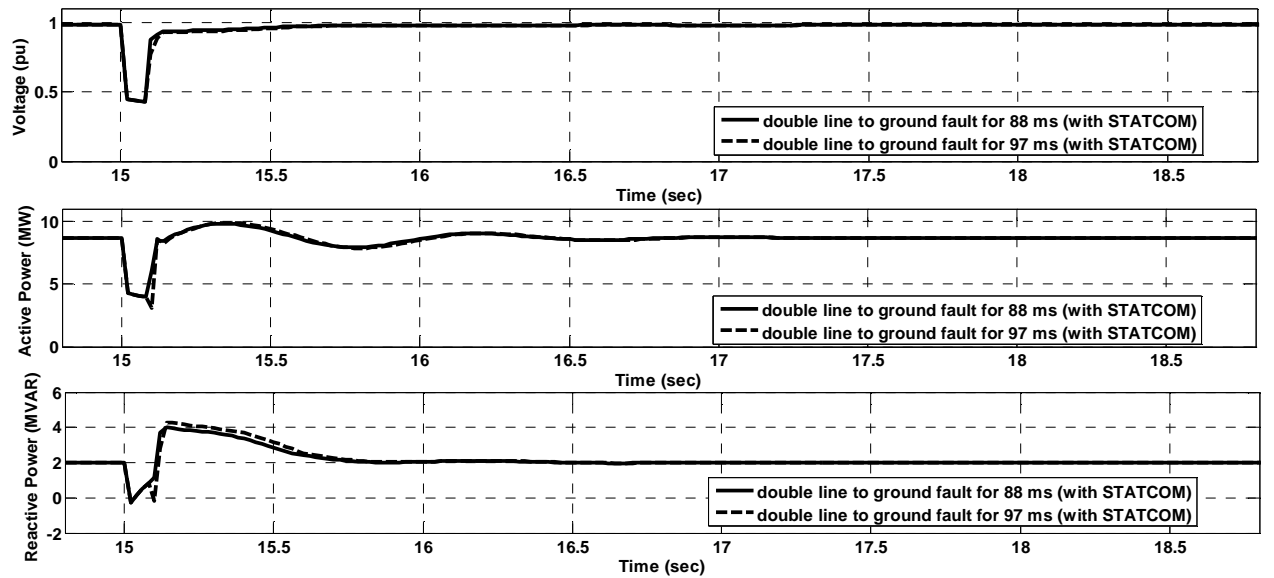

Fig. 12: The variations of the voltage, active power, and total absorbed reactive power during double line to ground fault at different fault durations - with STATCOM.

Figure 13 shows the behavior of the wind farm without STATCOM when a three line to ground fault occurs for $80 \mathrm{~ms}$ and $88 \mathrm{~ms}$ duration times. During fault period, the voltage of the main bus B25 falls to zero when the fault duration times are $80 \mathrm{~ms}$ and $88 \mathrm{~ms}$. When the fault duration time is equal or more than $88 \mathrm{~ms}$ the protection system trips the wind farm and the generated active power falls to zero. 

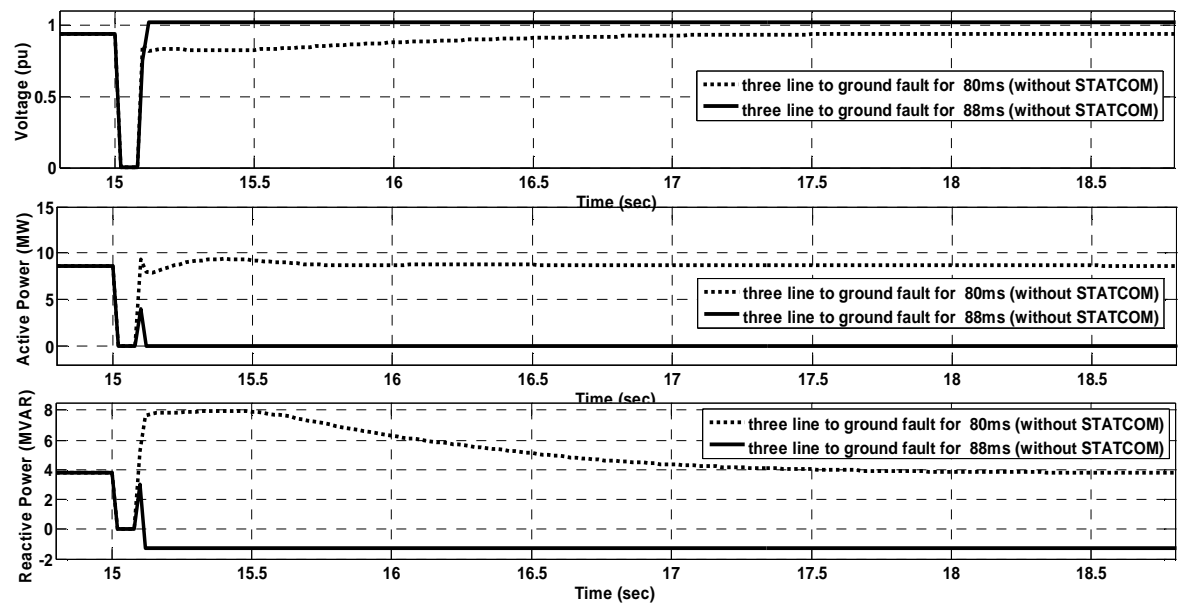

Fig. 13: The variations of the voltage, active power, and total absorbed reactive power during three-line to ground fault at different fault durations - without STATCOM.

During post fault period, the absorbed reactive power increased to 7.9810 MVAR for $80 \mathrm{~ms}$ fault duration. Where, the measured reactive power value is -1.2735 MVAR in the case of $97 \mathrm{~ms}$ fault duration and it leads to enhancing of the bus voltage value as shown in Fig. 13. When the STATCOM is disconnected, in case of three-line to ground fault with duration time of $88 \mathrm{~ms}$, the wind farm cannot stay connected to the grid and the protection system trips it from the grid.

Figure 14 shows the effect of three-line to ground fault duration time on the behavior of the wind farm in the presence of STATCOM. During fault period, the voltage of the main bus and the measured active power nearly falls to zero in cases of $80 \mathrm{~ms}$ and $88 \mathrm{~ms}$ fault duration times. During post fault period, the total absorbed reactive power from the grid is increased to $5.7585 \mathrm{MVAR}$ in case of $80 \mathrm{~ms}$ fault duration, and it increases to 6.1798 MVAR in case of $88 \mathrm{~ms}$ fault duration. It is clear that, in case of three line to ground fault, the wind power farm has the ability to stay connected under this fault condition with and without STATCOM connection either when the fault occurs for $80 \mathrm{~ms}$ or $88 \mathrm{~ms}$ duration time. Also, the system returns back to steady state operation after clearing the fault.
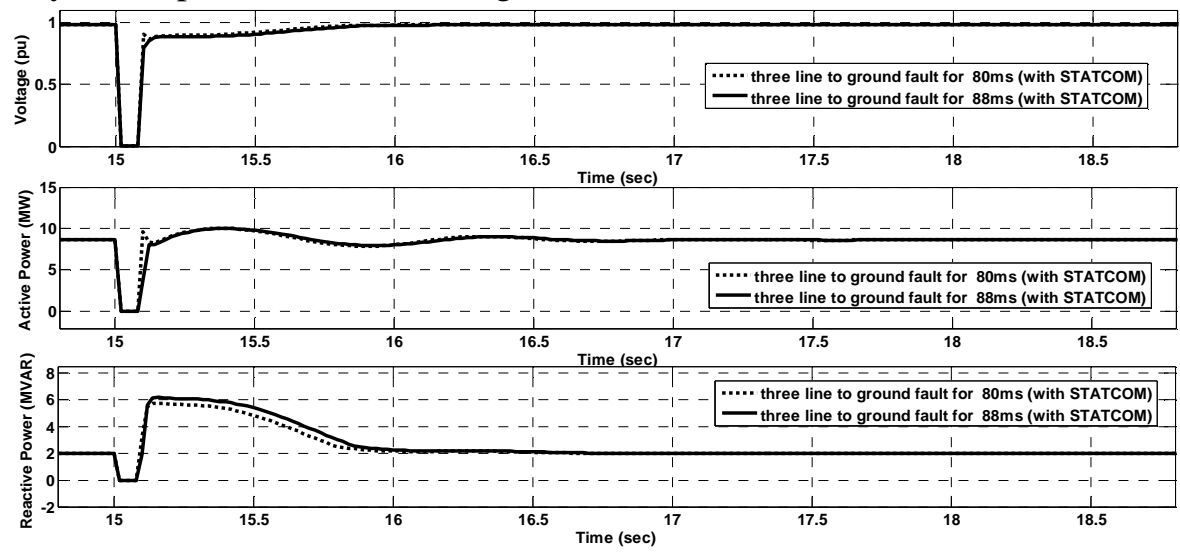

Fig. 14: The variations of the voltage, active power, and total absorbed reactive power during three-line to ground fault at different fault durations - with STATCOM. 


\section{CONCLUSIONS}

The effect of fault location and fault duration time on the behavior of the wind farm interconnected grid during different fault types is studied. Also, the impacts of the static synchronous compensator STATCOM on the stability of the system during different fault locations and different fault duration times are studied. A simulation model of 9 MW SCIG wind farm interconnected grid is investigated. The wind farm terminal voltage, the exported active power, and the absorbed reactive power are monitored in steady state and fault state conditions. The fault occurs at two fault locations $\mathrm{P} 1$ and $\mathrm{P} 2$, where $\mathrm{P} 1$ is located at $1 \mathrm{~km}$ from wind turbines and $\mathrm{P} 2$ is located at $26 \mathrm{~km}$ from wind turbines. By studying the effect of fault location, in the cases of single line to ground fault and double line to ground fault, the wind farm has the ability to stay connected under fault condition with or without STATCOM connection either when the fault occurs at points P1or P2 for $88 \mathrm{~ms}$ duration time. But in the case of three-line to ground fault with or without STATCOM the wind farm has ability to stay connected to the grid when the fault occurs at the point P2. In case of three-line to ground fault occurs at the point P1, the wind farm can stay connected to the grid only when the STATCOM is connected. By studying the effect of fault duration time, in case of single line to ground fault, the wind farm can stay connected to the grid in case of $80 \mathrm{~ms}$ and $150 \mathrm{~ms}$ fault duration times when the system operates with or without STATCOM. In case of double line to ground fault, when the system operates without STATCOM, the protection system trips the wind farm due to under-voltage condition in case of fault duration time equals or exceeds than $97 \mathrm{~ms}$. But when the STATCOM is connected, the system can return back to steady state and the wind farm can stay connected to the grid. In case of three line to ground fault, when the system operates without STATCOM, the protection system trips the wind farm due to under-voltage condition in case of fault duration time equals or exceeds than $88 \mathrm{~ms}$. But when the STATCOM is connected, the system can return back to steady state and the wind farm can stay connected to the grid. Finally, for the studied cases, in the presence of STATCOM the wind farm can stay connected to the grid when the fault location closed to the wind farm or when the fault duration time is increased.

\section{APPENDIX A}

The protection set parameters of SCIG wind turbine

\begin{tabular}{|c|c|c|c|c|}
\hline Parameter & $\begin{array}{l}\text { Minimum value } \\
(\mathrm{pu})\end{array}$ & & value & $\begin{array}{l}\text { Delay time } \\
\quad(\mathrm{sec})\end{array}$ \\
\hline AC under/over voltage & 0.75 & & & 0.1 \\
\hline Under/over rotor speed & 1 & & & 5 \\
\hline Parameter & \multicolumn{2}{|c|}{ Maximum value (pu) } & \multicolumn{2}{|c|}{ Delay time (sec) } \\
\hline AC current & \multicolumn{2}{|l|}{1.1} & \multicolumn{2}{|c|}{10} \\
\hline AC current unbalance & \multicolumn{2}{|l|}{0.4} & \multicolumn{2}{|c|}{0.2} \\
\hline Voltage unbalance & \multicolumn{2}{|l|}{0.05} & \multicolumn{2}{|c|}{0.2} \\
\hline
\end{tabular}




\section{REFERENCES}

[1] M.R. Patel, Wind and solar power systems, U.S. Merchant Marine Academy, Kings Point, New York, 1999.

[2] V. Akhmatov, H. Knudsen, A. H. Nielsen, J. K. Pedersen, N. K. Poulsen, Modelling and transient stability of large wind farms, International journal of electrical power and energy systems 25(2), 2003, pp. 123-144.

[3] Z. Chen, Y. Hu, F. Blaabjerg, Stability improvement of induction generator-based wind turbine systems", IET Renewable Power Generation 1, (1), 2007, pp. 81-93.

[4] O. Noureldeen, Characteristics of fixed speed wind turbines interconnected grid during wind speed variations", 13th Middle East Power Systems Conference MEPCON, 2009, pp. 220-225.

[5] H. Livani, M. Bandarabadi, Y. Alinejad, Improvement of fault ride-through capability in wind farms using VSC-HVDC, European Journal of Scientific Research 28, (3), 2009, pp. 328-337.

[6] A. A. El-Sattar, N. H. Saad, M. Z. Shams El-Dein, Dynamic response of doubly fed induction generator variable speed wind turbine, Science direct, electric power system research (78), 2008, pp. 1240-1246.

[7] F. Iov, A. Daniela Hansen, P. Sorensen, F. Blaabjerg, Wind turbine block-set in MATLAB/Simulink, Aalborg university and RISØ national laboratory, 2004.

[8] C. Chompoo, C. Yingvivatanapong, K. Methaprayoon, Reactive compensation techniques to improve the ride-through capability of wind turbines during disturbance, IEEE transactions on industry applications 41, (3), 2005, pp. 666672.

[9] D. J. Trudnowski, A. Gentile, J. M. Khan, E. M. Petritz, Fixed-speed windgenerator and wind-park modelling for transient stability studies, IEEE Trans. on Power Systems 19, (4), 2004, pp. 1911-1917.

[10] E. Muljadi, Z. Mills, R. Fosser, J. Conto, A. Ellis, Fault Analysis at a wind power plant for one year observation, IEEE Power and Energy Society General Meeting, 2008.

$$
\begin{aligned}
& \text { تأثثر مكان حدوث القصر ومدته الزمنية علي استقرار مزرعة الرياح الموصلة بالثبكة } \\
& \text { هذا البحث يدرس نأثثرات القصر علي استقرار مزرعة رياح ذات سرعة ثابتة منصلة بالثبكة الكهربية. تم دراسة }
\end{aligned}
$$

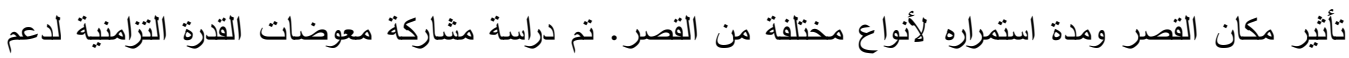

$$
\begin{aligned}
& \text { مزرعة الرياح عند حدوث القصر عند أماكن مختلفة وكذلك مدة استمرار مختلفة. الحالات التي تم دراستها تم } \\
& \text { تمثيلها بواسطة برنامج (MATLAB) وذلك لمزرعة رياح قدرتها } 9 \text { ميجا وات موصلة بشبكة ذات جهر } 120
\end{aligned}
$$

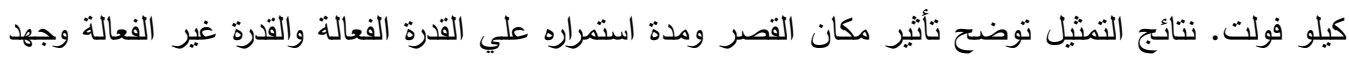

$$
\begin{aligned}
& \text { مزرعة الرياح. }
\end{aligned}
$$

